\section{Southwest Plant Selector: A Mobile App for Homeowners}

\author{
Stefan Sutherin ${ }^{1}$, Kevin Lombard ${ }^{2}$, and Rolston St. Hilaire ${ }^{1,3}$
}

\begin{abstract}
AdDitional INDEX wORDs. iTunes $^{\circledR}$, landscape plants, landscape water conservation, smartphone, tablets, usability test, xeriscape

SumMARY. To fill a critical need for more information on desert-adapted low wateruse landscape plants, we created Southwest Plant Selector, a mobile plant selector application (app) of landscape plants from the New Mexico Office of the State Engineer (NMOSE) online database of New Mexico landscape plants. The app, which is available for Apple ${ }^{\circledR}$ iPhone $^{\circledR}$ and $\mathrm{iPad}^{\circledR}$, was designed for homeowners and lists plant descriptive items, pest and disease information, and a photograph of the plant. The app also displays a graphic of the three regions of New Mexico and El Paso County, TX, overlaid with text that provides plant water requirements for each of those regions. An associated web page allows users to calculate supplemental plant water requirements for individual plant selections. Homeowners can select landscape plants based on botanical or common name, plant type, and category, region, and sun exposure. Even with the specific user base of New Mexico residents who own Apple ${ }^{\circledR}$ mobile devices, the app has been downloaded nearly 5000 times since its first release on 29 June 2012. New Mexico State University (NMSU) Cooperative Extension Service agents now use the app as a part of their standard toolkit for interactions with homeowners. Mobile technologies such as smartphone and tablet apps are gaining prominence as outreach tools. Land-grant institutions can be more involved in leveraging mobile application technologies for education and outreach. This article describes a process that land-grant institutions can use to produce apps for horticulture outreach.
\end{abstract}

$\mathrm{H}$ orticulturists find it challenging to disseminate regionally relevant information on landscape plants to homeowners in New Mexico because the state is climatologically diverse and geographically expansive. The U.S. Department of Agriculture (USDA) hardiness zones range from four in northern, higher

The New Mexico Office of the State Engineer (NMOSE) plant database development was funded in part by a grant from the U.S. Bureau of Reclamation. This work was funded in part by a grant from the Rio Grande Basin Initiative, a collaborative research program of NMSU and Texas A\&M University awarded to K.L. and R.S.H.

We thank Jeanne Gleason, Barbara Chamberlain, John Chamberlin, Connie Padilla, and the staff of the New Mexico State University (NMSU) Media Productions and Learning Games Lab, part of the NMSU Cooperative Extension Service for technical assistance. We gratefully acknowledge Dan Smeal for assisting with the development of the Southwest Plant Selector Water Calculator. We also thank John Longworth and Cheri Vogel of the NMOSE for permitting the use of plant database.

Use of trade names does not imply endorsement of the products named or criticism of similar ones not named.

${ }^{1}$ Department of Plant and Environmental Sciences, New Mexico State University, Box 30003, Las Cruces, NM 88003

${ }^{2}$ Department of Plant and Environmental Sciences, Agriculture Science Center at Farmington, New Mexico State University, Box 1018, Farmington, NM 87499

${ }^{3}$ Corresponding author. E-mail address: rsthilai@nmsu. edu. Cupertino, CA) and $\mathrm{Chomp}^{\circledR}$ (San Francisco, CA) revealed just a few database-driven plant selectors. None included landscape plants suited to New Mexico landscapes or even the southwestern U.S. (Nevada, California, Utah, New Mexico, and Arizona). Apple $^{\circledR}$ acquired Chomp ${ }^{\circledR}$ in Feb. 2012 and shut down the autonomous Chomp ${ }^{\circledR}$ website in Oct. 2012 (Zibreg, 2012). An app would extend the center's horticultural information to mobile users. In early 2012, a total of $34 \%$ of mobile users in the United States used apps, and $25 \%$ of mobile web users were mobile only, meaning that they did not use laptop or desktop computers (mobiThinking, 2012). Over $85 \%$ of new cell phone handsets were mobile capable and about half of those handsets were smartphones (mobiThinking, 2012). The share of mobile users is expected to rise. Apple ${ }^{\circledR}$ and Google $\mathrm{T}^{\mathrm{TM}}$ (Mountain View, CA) are currently the major players in the extremely dynamic app market.

Apps must be tested for functionality (how well they work), general acceptability, and usability. Protocols designed for website testing are also suited to mobile app testing. For example, usability, which is the capability of the software product to be understood, comprehended, used, and attractive to the user when used under specified conditions (International Organization for Standardization, 2009), is tested similarly for mobile apps and websites. Usability issues include navigation, screen appearance, accessibility, and consistency (Teoh, 2009). For usability testing, three to five handson testers uncover as many problems as five or more testers. Furthermore, iterative testing with a few testers uses resources more efficiently than a single test with many subjects. For lowbudget projects, two testers can be optimal (Nielsen, 2012).

The objective of this article is to detail how a unique horticultural mobile app was created to assist homeowners in selecting landscape plants that thrive in distinct climate regions of New Mexico and El Paso County, TX, with little or no supplemental irrigation. We also explain how the app was tested for

\begin{tabular}{llll}
\hline $\begin{array}{l}\text { Units } \\
\begin{array}{l}\text { To convert U.S. to SI, } \\
\text { multiply by }\end{array}\end{array}$ & U.S. unit & SI unit & $\begin{array}{l}\text { To convert SI to U.S., } \\
\text { multiply by }\end{array}$ \\
\hline 0.3048 & $\mathrm{ft}$ & $\mathrm{m}$ & 3.2808 \\
25.4 & inch(es) & $\mathrm{mm}$ & 0.0394
\end{tabular}


functionality, general acceptability, and usability as an educational outreach tool for homeowners.

\section{Materials and methods}

Developing Southwest Plant Selector. Southwest Plant Selector used the NMOSE's New Mexico plant list database (NMOSE, 2011). The database design was suited to an app format because the fields were separately identified and set up in a searchable index. The database had 745 plant entries, each defined by 12 criteria: botanical/common/alternate names, region [northern, central, southern (area within New Mexico to which the plant is best suited)], category (tree, shrub, annual, perennial, turfgrass, ornamental grass, groundcover, cactus/succulent/desert accent, vine), type (evergreen/deciduous/ semideciduous), bloom color and time, exposure (sun/shade/partial), size, soil type, water requirement, animal/pest attractions, and a general description.

We selected NMSU Learning Games Laboratory, as the vendordeveloper because of our history of collaboration and their competitive development fee. We did a cost-benefit comparison of Apple ${ }^{\circledR}$, Android ${ }^{\mathrm{TM}}$ (Google $^{\mathrm{TM}}$ ), Blackberry ${ }^{\circledR}$ (Waterloo, ON, Canada), and Microsoft ${ }^{\circledR}$ (Redmond, WA) platforms and selected the Apple ${ }^{\circledR}$ platform because of its dominant market share at the time (Roberts and McIntosh, 2012), ease of use, and software stability.

A developer from the NMSU Learning Games Laboratory was responsible for developing the app and navigating the iTunes ${ }^{\circledR}$ approval process. The original NMOSE plant database was in Microsoft Access ${ }^{\circledR}$ and was reformatted to a SQLite database. SQLite is a free public domain database software (SQLite, 2013). After database reformatting, Apple ${ }^{\circledR}$ iOS SDK (Version 4.2) was used to develop the app.

To allow the information to fit the display screens of the $\mathrm{iPad}^{\circledR}(\mathrm{Ap}-$ ple $\left.^{\circledR}\right)$ and the iPhone ${ }^{\circledR}\left(\right.$ Apple $\left.^{\circledR}\right)$, the sort criteria was pared from 12 to 5: 1) botanical or common name, 2) plant type (evergreen/deciduous/ semi), 3) category (tree, shrub, etc.), 4 ) region (north, central, or south), and 5) sun exposure (sun/shade/ partial). We judged these criteria to be most relevant to plant selection decisions. Also, at 745 plant entries, the database was relatively small and returned few entries with increased sort selections.

We created a display in the app that consisted of an overlay of a graphic of the three regions of New Mexico with text that gave the supplemental water requirements for each region. After several iterations, we settled on text that now includes the following: not suitable for xeriscaping; precipitation only; little or no supplemental water; $1 \times$ per month or $2 \times$ in summer. iTunes ${ }^{\circledR}$ requires a dedicated support website and a support e-mail address. Southwest Plant Selector has a dedicated website and support e-mail address (Southwest Plant Selector, 2013). The support page is simple so that little, if any, maintenance will be required; it was patterned after similar app support pages on iTunes ${ }^{\circledR}$.

Evaluating Southwest Plant Selector. At the late stages of development, a beta version of the Southwest Plant Selector app was uploaded to TestFlight (2013), an online resource that allows developers to beta test their iOS apps before launch. Testers' devices are identified and permitted by the developer to install specified apps. The developer tested functionality and general acceptability of the app using TestFlight with our staff and his peer network.

Two individuals who had previously participated in website usability tests for the Center for Landscape Water Conservation were recruited to test the app. The usability test was conducted immediately after launch, but before we publicized the app. The test required the users to complete and respond to specific tasks involving navigation and search, which are the primary functions of this app. Testers were also asked to assess content, such as whether plant descriptions were adequate for homeowner decision making. Testers then completed a survey using the online service, Survey Console (2013). An example of a suite of tasks developed to test the intuitiveness of the navigation was, "scan the full (plant) list, set criteria to make selections, save selections to favorites, and edit your favorite list." After completing these tasks, testers were asked to detail any nonintuitive steps or navigation problems. The Institutional Review Board at NMSU approved the survey procedures that involved human participants.
After the app was launched, we collected and analyzed ratings and reviews from the iTunes ${ }^{\circledR}$ app store, and download data via Mopapp ${ }^{\mathrm{TM}}$ (2013) to further evaluate the app. Mopapp $^{\mathrm{TM}}$ is a free online app analytics service that provides download data on the app. Mopapp ${ }^{\mathrm{TM}}$ was preferred for this project because, at the time, the free version allowed the data to be downloaded and distributed as PDF files; currently, there are other services that provide as-good or better downloadable data. In addition, we noted verbal and e-mail suggestions as important qualitative indicators for a possible future upgrade.

Marketing Southwest Plant Selector. On 25 Feb. 2012, the app, still in development, was piloted at the 16th Water Conservation/Xeriscape Conference and Expo in Albuquerque, NM. We showed the app to individual vendors by walking boothto-booth with an $\mathrm{iPad}^{\circledR}$ and allowing them hands-on use. At the initial app launch of 29 June 2012, NMSU Media Relations generated both a print and a video press release, which were distributed through their media outlets. The app support page link and an iTunes ${ }^{\circledR}$ link were posted on the Center for Landscape Water Conservation website and Facebook ${ }^{\circledR}$ page, on Twitter ${ }^{\circledR}$, and on the NMSU College of Agricultural, Consumer, and Environmental Sciences home page. The link was also posted on the NMOSE plant list page and distributed to NMOSE contacts. Announcements and flyers, which included a quick response $(\mathrm{QR})$ code linked to the iTunes ${ }^{\circledR}$ page, were distributed to regional nurseries, posted on NMSU bulletin boards, forwarded through the NMSU Cooperative Extension Service network, and e-mailed to NMSU branch campuses and municipal water conservation offices throughout New Mexico.

\section{Results and discussion}

Developing Southwest Plant Selector. Project costs are given in Table 1 . We spent $120 \mathrm{~h}$ reviewing the database and preparing it for development. An additional 80 h of our time was spent on photograph clean up and sourcing readily available photos. Some of the acquired photos required editing and cropping. This added $\$ 500$ to the original subcontracted costs. About $10 \mathrm{~h}$ were used 
Table 1. Development, marketing, and support costs of Southwest Plant Selector, a mobile landscape plant selector application created for homeowners in New Mexico and El Paso, TX.

\begin{tabular}{llr}
\hline Task & \multicolumn{1}{c}{ Cost element } & \multicolumn{1}{c}{ Cost (\$) } \\
\hline Development & New Mexico State University learning & \\
& Games Laboratory subcontract & 5,500 \\
& Student wages & 3,000 \\
Marketing & Demonstration of app at regional conference & \\
& Transportation, lodging, student labor & 575 \\
Support & Wages for photograph upgrade and support & \\
& New Mexico State University learning & \\
& Games Laboratory subcontract- & 1,000 \\
Total costs & & 10,075
\end{tabular}

${ }^{2}$ Sixteenth Water Conservation/Xeriscape Conference and Expo at the Albuquerque Convention Center, Albuquerque, NM. We shared a booth with the New Mexico Office of the State Engineer at the Expo and had no booth charges.

${ }^{y}$ Costs exclude iTunes ${ }^{\circledR}$ (Apple ${ }^{\circledR}$, Cupertino, CA), annual charge (typical fee is $\$ 99$ per year) because the app is hosted for free on an existing New Mexico State University iTunes ${ }^{\circledast}$ development page.

to develop the Apple ${ }^{\circledR}$-required support page, including administrative time to research and write the content.

Plant listings displayed well on the $\mathrm{iPad}^{\circledR}$ (Fig. 1A) and on the iPhone ${ }^{\circledR}$ (Fig. 1B). Regional watering requirements and plant details for each plant are available on the $\mathrm{iPad}^{\circledR}$ (Fig. IC and D). Plant details and watering schedules also were displayed on the iPhone ${ }^{\circledR}$ (Fig. 2A-D). Users download the app regularly; 4928 downloads as of 4 June 2013 (Fig. 3). The app, denoted by a pink flower with a ray and disc arrangement (Fig. 4A), can be downloaded at the iTunes ${ }^{\circledR}$ app store (Southwest Plant Selector, 2012), or by scanning its QR code (Fig. 4B). Southwest Plant Selector is a native app, which means that all data resides entirely on the device, so it does not require connectivity when in use.

The NMOSE database was well suited to an app format and the database structure transitioned easily to an app structure. The compatible data structure significantly reduced the cost and effort required to develop the app. App developers wishing to use an existing database should verify the data structure before proceeding with development to determine the level of effort required for reformatting. Even if the database is structured correctly, developers should also review the quality of the content to ensure its integrity.

In our case, the NMOSE database content was reviewed for quality assurance. The most obvious homeowner-related content errors were corrected so the app could be released. An additional review cycle was undertaken postlaunch to fix user issues and to complete a multilevel review that included updating plant scientific names.

About half of the photographs from the original database displayed well on the computer screen, but were blurry on the high-resolution iPad ${ }^{\circledR}$ screen. We resized low-resolution photographs for best display and replaced about a third with photographs that were readily available within the NMSU system. The blurriest pictures were primarily in the $200 \times 200$ pixel range. We estimate that $\approx 250$ of the current plant entries would benefit from a photograph upgrade. For plants destined for display on the iPad ${ }^{\circledR}$ or other high-resolution tablet screen, we recommend using photographs of the highest possible resolution, but certainly not less than $200 \times 200$ pixels. We cannot specify a minimum photograph resolution because of continuing improvements to $\mathrm{iPad}^{\circledR}$ screen resolution; what is minimally acceptable today may be unacceptable tomorrow.

Marketing Southwest Plant Selector. The decision to offer Southwest Plant Selector as a free app with no in-app purchase or upgrade features was initially driven by the NMOSE inability to legally charge for its data. A review of app pricing information showed the free price point to be in line with the current trend for similarly categorized apps. Competition-driven downward pressure on app prices, coupled with producers' and users' move toward free apps show that price should be in line with apps that are similar in category, capability, and complexity (Koekkoek, 2011).
Vendors received the app enthusiastically when the app was piloted at the 16th Water Conservation/ Xeriscape Conference attesting to the niche that the app fills in New Mexico. Eleven vendors asked to be notified when the app launched, while four volunteered to provide additional plant photographs. Behe et al. (2013) reported that gardeners who search online for garden-related information and products are more likely to make a garden-related purchase. New Mexico vendors of drought tolerant, water conserving plant material would therefore seemingly benefit through increased sales, which explains their enthusiasm for Southwest Plant Selector. We planned seasonal promotional events for the app. For this type of app, promotion activities can include press releases, social media, online review services, appropriate keywords for search purposes, demonstration videos, and professional-looking web support pages (Viswanathan, 2012). We used all the above recommended avenues to promote the Southwest Plant Selector app postlaunch except for the submission to online review sites. Because the app was specific to the New Mexico region, we judged that it did not warrant submission to online review sites.

Evaluating Southwest Plant Selector. TestFlight users encountered difficulty with navigation between the "Criteria" screen and the "Favorites" screens, and in resetting the Criteria screen for a new search. TestFlight testers also identified improvements to the regional graphic depicting the climate regions with the associated water requirements.

Like the TestFlight evaluation, usability testing uncovered issues with the search and navigation, which would require minor software corrections (Table 2). Survey Console data indicated that the navigation steps "scan the full (plant) list, set criteria to make selections, save selection to favorites, and edit your favorites list," involved clearing previously set criteria and returning back to the full plant list, which was not intuitive, causing testers to ponder each navigation step. The navigation process was improved in the following upgrade to make it more intuitive.

Another suggestion from users who completed this task was to "make the heart emblem larger so that it 


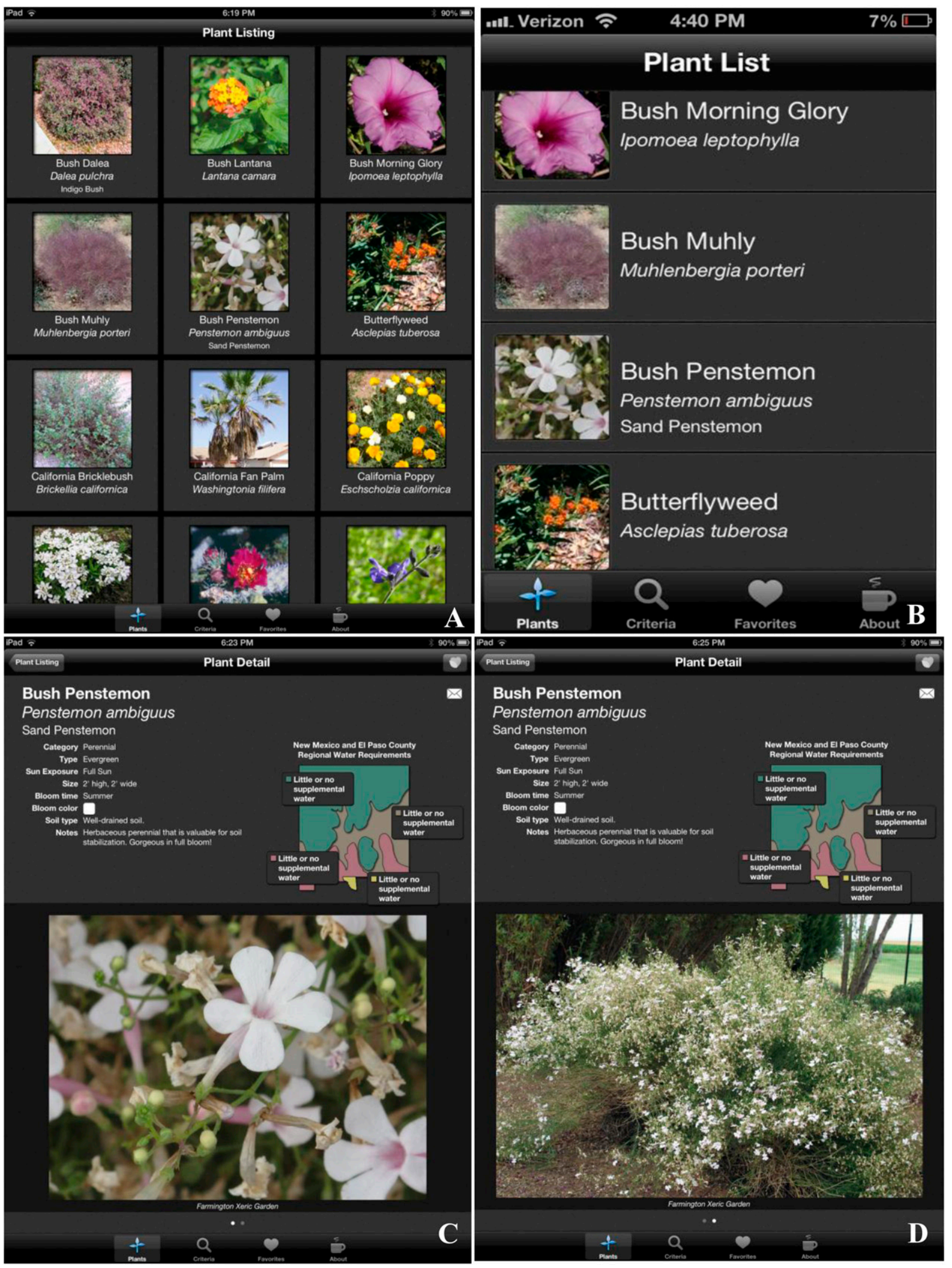

Fig. 1. (A) Screen capture of plant listings from the plant listing screen of the Southwest Plant Selector mobile application as displayed on the $\mathrm{iPad}^{\circledR}\left(\right.$ Apple $^{\circledR}$, Cupertino, CA). Southwest Plant Selector is a mobile landscape plant selection application created for homeowners in New Mexico and El Paso County, TX. (B) Screen capture of plant listings from the plant listing screen of the Southwest Plant Selector mobile application as displayed on the iPhone ${ }^{\circledR}$ (Apple ${ }^{\circledR}$ ). (C) Screen capture of plant detail and image from the plant detail screen of the Southwest Plant Selector mobile application as displayed on the iPad ${ }^{\circledR}$ $\left[2^{\prime}(\right.$ i.e., $\left.2 \mathrm{ft})=0.61 \mathrm{~m}\right]$. (D) Screen capture of plant detail along with a second plant image from the plant detail screen of the Southwest Plant Selector mobile application as displayed on the iPad ${ }^{\circledR}$. 


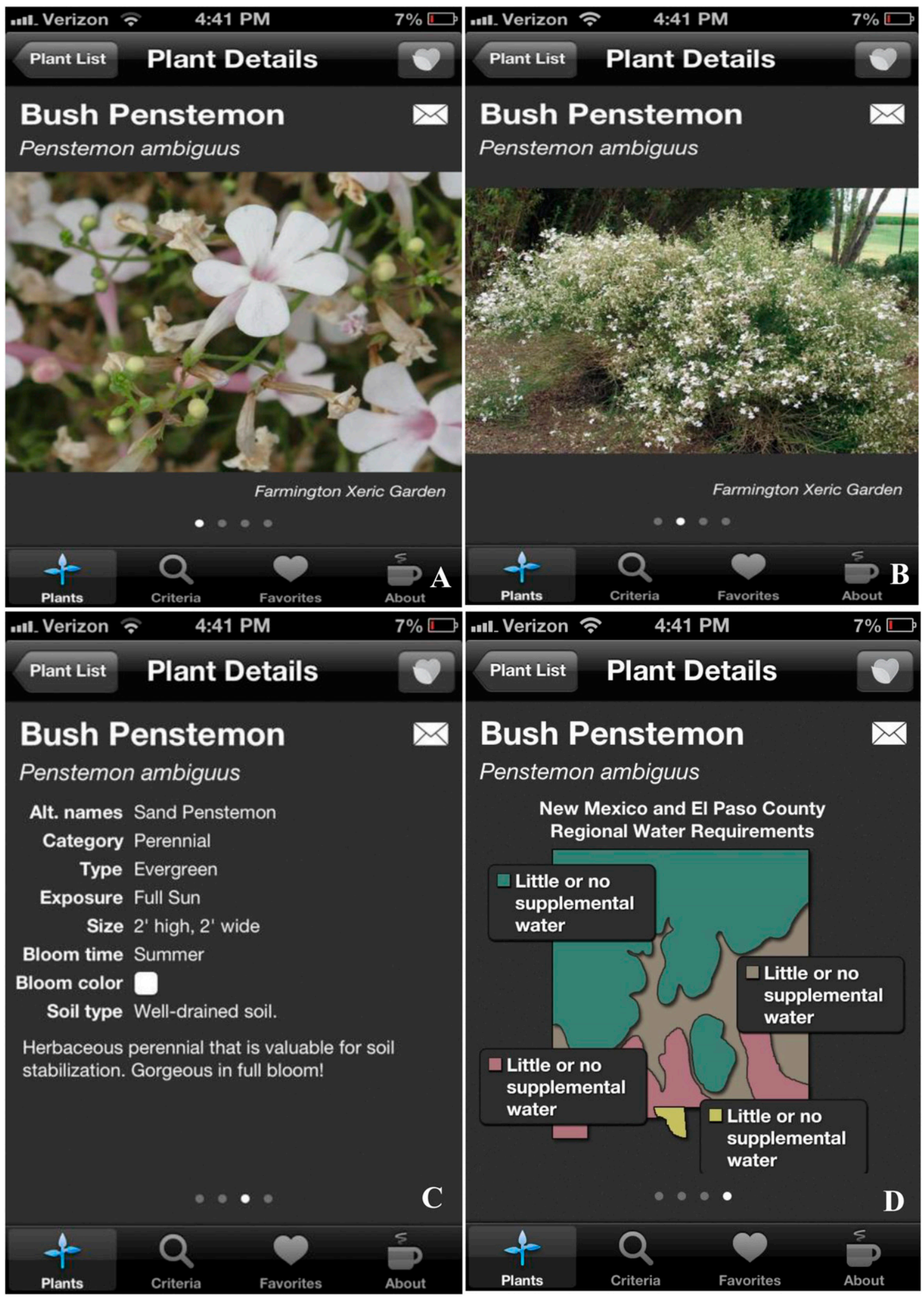

Fig. 2. (A) Screen capture of plant image from the plant detail screen of the Southwest Plant Selector mobile application as displayed on the iPhone ${ }^{\circledR}\left(\right.$ Apple ${ }^{\circledR}$, Cupertino, CA). Southwest Plant Selector is a mobile landscape plant selection application created for homeowners in New Mexico and El Paso County, TX. (B) Screen capture showing a second plant image from the plant detail screen of the Southwest Plant Selector mobile application as displayed on iPhone ${ }^{\circledR}$. (C) Screen capture of plant detail from the plant detail screen of the Southwest Plant Selector mobile application as displayed on the iPhone ${ }^{\circledR}\left[2^{\prime}\left(i . e .,{ }^{2} \mathrm{ft}\right)=\right.$ $0.61 \mathrm{~m}$ ]. (D) Screen capture of regional watering detail from the plant detail screen of the Southwest Plant Selector mobile application as displayed on the iPhone ${ }^{\circledR}$. The watering detail shows that the plant requires little or no supplemental water in all the regions displayed. 


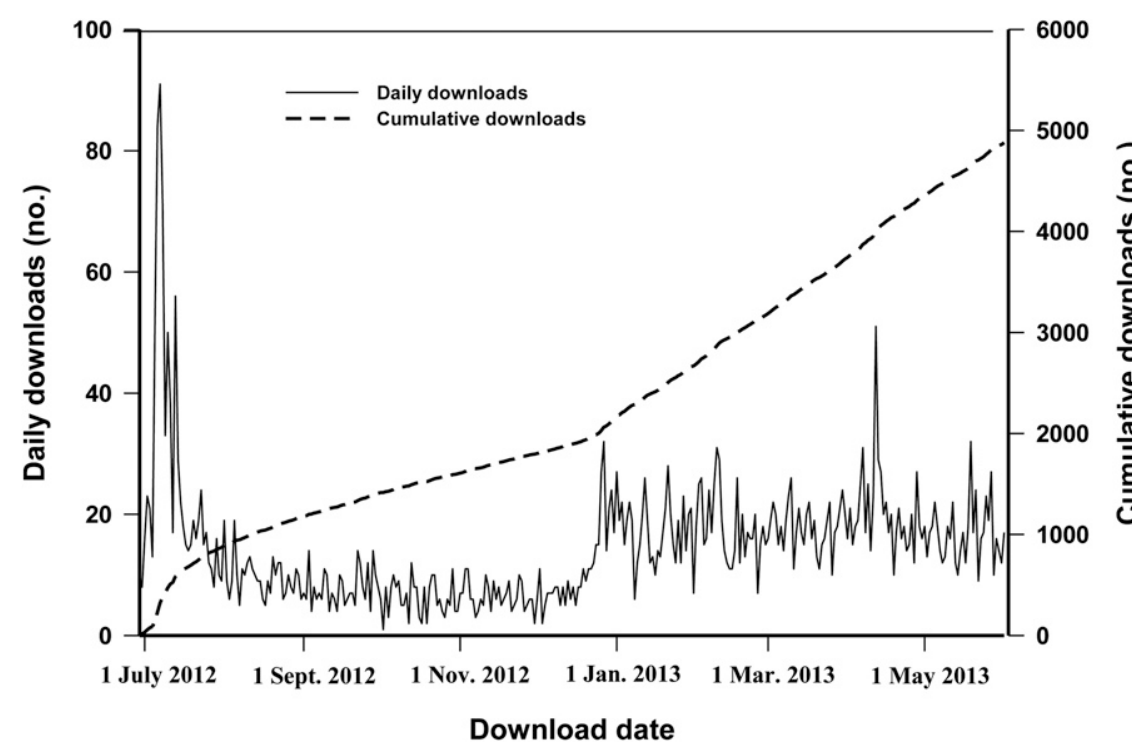

Fig. 3. Southwest Plant Selector daily and cumulative downloads from 29 June 2012 to 4 June 2013. Southwest Plant Selector is a mobile landscape plant selection application created for homeowners in New Mexico and El Paso County, TX. Data were collected automatically by $\operatorname{Mopapp}^{\mathrm{TM}}$ (Mopapp, 2013).

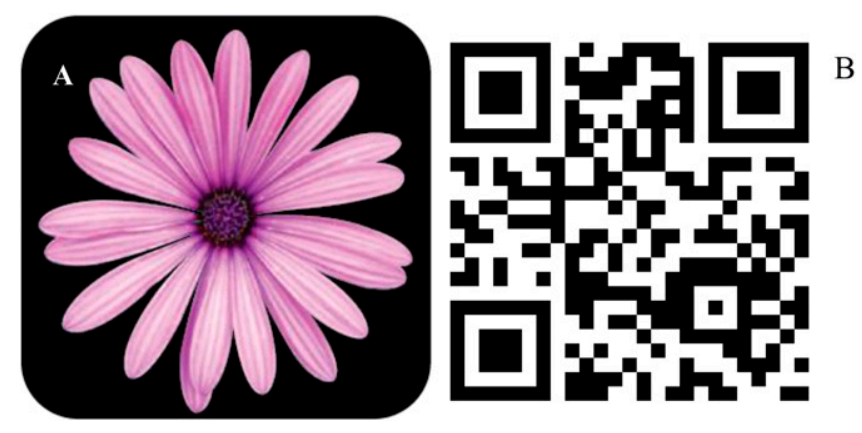

Fig. 4. (A) Southwest Plant Selector app display icon for the iPad ${ }^{\mathrm{TM}}\left(\right.$ Apple $^{\circledR}$, Cupertino, CA) and iPhone ${ }^{\circledR}\left(\right.$ Apple $\left.^{\circledR}\right)$. Southwest Plant Selector is a mobile landscape plant selection application created for homeowners in New Mexico and El Paso County, TX. (B) Quick response (QR) code for the Southwest Plant Selector. A scan of the $Q R$ code with a $Q R$ code reader open an iTunes ${ }^{\circledR}$ page that allows the user to download the app directly to a mobile device.

stands out a bit." The heart emblem allows the users to click on it to add a plant to a favorites list. Another issue was that the search tool does not key on partial terms or single words in a phrase; it cannot find "pine trees," but it will retrieve pine trees using the search word "pine." Actions recommended to correct concerns that were raised during usability testing are given in Table 2 .

One of the minor changes we made during testing was to reorder descriptive items that accompany each plant. The main page of the app lists plant descriptive items along with a photograph of the plant. The original list of descriptive items was in random order and now follows a consistent flow based on user significance. The current rank order of descriptive items is category, type, sun, size, bloom time, bloom color, soil, and notes.

The testers gave the app positive reviews. For example, the tester who was a master gardener concluded, "It's very easy to use and the photos are good. Plus you don't have to wade through info on plants that are more appropriate to other areas."

Initial iTunes ${ }^{\circledR}$ user ratings included five 5-star ratings and three 4-star ratings. These eight iTunes ${ }^{\circledR}$ reviewers (Table 2 ) all had positive comments, using accolades to include
"Very useful tool! I've been looking for something like this for a while now." iTunes ${ }^{\circledR}$ reviews and usability test responses point to minor corrections and specific requests to consider in a subsequent upgrade (Table 2 ).

Additional verbal and e-mail feedback requests from users included add ability to sort on color; add the El Paso region (area in Texas that borders southern New Mexico); add video clips from NMSU Southwest Yard and Garden; add vegetables; add Android ${ }^{\mathrm{TM}}$ format; add disease and toxicity information; further clarify watering requirements. Users also have verbally requested that we make the photographs pull out to full screen. Users are most satisfied with $\mathrm{iPad}^{\circledR}$ apps that leverage the device's ability to display beautiful images, but they are dissatisfied when they are unable to zoom on those images (Nielsen and Buidu, 2010).

Based on the initial postlaunch testing and user feedback, the first upgrade of Southwest Plant Selector was completed. The upgrade, version 1.06, launched on 26 May 2013. Homeowners can now select plants for El Paso County, TX, which shares some ecological characteristics with southern New Mexico. Plants can now be sorted on color by selecting a color chip and a homeowner can now e-mail a plant summary. Misnomers and other content errors in the plant database were corrected. Settings now allow users to work in the scientific mode, which orders the plants by scientific name. We added pest and disease information and upgraded $\approx 100$ images. A web-based support page was developed to allow users to specifically calculate supplemental water requirements for individual plants (NMSU, 2013).

Southwest Plant Selector download data from the 29 June 2012 launch through 4 June 2013 shows the download data trend (Fig. 4). Higher download numbers initially correlate with promotional activities at launch followed by a fairly steady pattern postlaunch. Download increases associated with Christmas 2012 promotions show some durability through 2013. Southwest Plant Selector was downloaded 4928 times from launch through 4 June 2013. In addition, Southwest Plant Selector won the gold award in the Interactive Media Program category and an 
Table 2. Summary of the evaluation of Southwest Plant Selector, a mobile landscape plant selector application created for homeowners in New Mexico and El Paso, TX, which shows the problems identified and recommended corrective action for the usability test and iTunes ${ }^{\circledR}$ (Apple ${ }^{\circledR}$, Cupertino, CA) comments. Usability is a measure of the appeal and the ease with which a user understands, learns, and uses a software product when the product is used under specified conditions.

\begin{tabular}{|c|c|c|c|}
\hline$\underline{\text { Evaluation }}$ & Category & Problem identified & Recommended corrective action \\
\hline Usability & Search & $\begin{array}{l}\text { Search does not pick up partial entries e.g., } \\
\text { "pine tree" did not find "pine" trees }\end{array}$ & $\begin{array}{l}\text { Allow association with parts of compound } \\
\text { words. Actual: This is a costly fix and will } \\
\text { wait until a future upgrade }\end{array}$ \\
\hline Usability & Search & $\begin{array}{l}\text { Plant category, “other plant” yields no } \\
\text { results }\end{array}$ & Delete “other plants.” Actual: Complete \\
\hline Usability & Search & Heart icon for "favorite" is not obvious & $\begin{array}{l}\text { Make heart red. Actual: "Favorites" icon } \\
\text { now goes to directions on how to use it }\end{array}$ \\
\hline iTunes ${ }^{\circledR}$ comments & Search & $\begin{array}{l}\text { Would like to see bloom colors, butterfly and } \\
\text { hummingbird attractors, deer and bunny } \\
\text { resistance, toxicity for dogs and cats }\end{array}$ & $\begin{array}{l}\text { Icons for those should be considered for } \\
\text { future update. Actual: Color icons } \\
\text { implemented }\end{array}$ \\
\hline iTunes $^{\circledR}$ comments & Search & Add more insect information & $\begin{array}{l}\text { Possibly a future update, but will require } \\
\text { volunteer labor }\end{array}$ \\
\hline
\end{tabular}

honorable mention in Best Innovative Use of Communication Technology in the Association for Communication Excellence in Agriculture, Natural Resources, and Life and Human Sciences 2013 Critique and Awards Program; it contends next for the top award in the Technology category.

\section{Limitations}

This project formed the basis of further work to inform mobile connected New Mexico homeowners of low water-use plant options in their landscape. Nevertheless, projects such as this are conducted within financial and human constraints and there were notable limitations of this study: Because different handset brands require unique development efforts for the same app, we could fund the development of only one app format. When we are financially able and the rest of the images are upgraded, we intend to produce an Android ${ }^{\mathrm{TM}}$ version. Meanwhile, the app will be made available on a mobile-adapted website. Although the website will require internet connectivity, the information will at least be more widely available.

\section{Conclusions}

Southwest Plant Selector dovetailed with the existing online outreach resources of the Center for Landscape Water Conservation and filled a void in the rapidly evolving market for a mobile resource to educate users on landscape plants appropriate to their region. Although we were fortunate to have access to a well-developed database, a thorough initial review of existing or potential databases is needed to understand potential issues with data quality and labor cost of the project. According to the NMOSE, the database development cost was $\$ 30,000$, funded in part with a $\$ 15,000$ grant from the U.S. Bureau of Reclamation that required equal matching funds (J. Longworth, personal communication). Development cost of the Southwest Plant Selector would have been cost prohibitive without the use of the existing database. So, one strategy for cost-effective educational app development would be to configure existing information and data to an app format and seek development team members with similar goals. In our case, our aim and that of our partner was to disseminate information on landscape plants and landscape water conservation to residents of New Mexico.

\section{Literature cited}

Behe, B.K., B.L. Campbell, C.R. Hall, H. Khachatryan, J.H. Dennis, and C. Yue. 2013. Smartphone use and online search and purchase behavior of North Americans: Gardening and nongardening information and products. HortScience 48:209-215.

Center for Landscape Water Conservation. 2013. Center for Landscape Water Conservation. 28 June 2013. <http:// www.xericenter.com/main.php $>$.

International Organization for Standardization. 2009. International Standards for HCI and Usability. 8 Sept. 2009. <http://www.usability.net.org/tools/ r_international.htm>.

Koekkoek, H. 2011. Distimo Blog. 4 July 2012. <http://www.distimo.com/ blog/2011_09_distimo-presentationfrom-vdc-conference-pricing-for-success $/>$.

mobiThinking. 2012. Global mobile statistics 2012 part e: Mobile apps, app stores, pricing and failure rates. 10 May 2012. <http://mobithinking.com/ mobile-marketing-tools/latest-mobilestats $>$.

Mopapp. 2013. Analytics Dashboard, Application Details. 14 Mar. 2013. <https://www.mopapp.com/my/ report? $\mathrm{c}=$ USD\&from $=20120629 \&$ to $=$ $20120829 \&$ gid $=17048 \&$ s $=2147483648$ $\& g=3>$.

New Mexico Office of the State Engineer. 2011. New Mexico Plant List-Office of the State Engineer. 11 July 2013. <http://wuc.ose.state.nm.us/Plants/>.

New Mexico State University. 2013. Southwest Plant Selector Water Calculator. 29 June 2013. <http://desertblooms. nmsu.edu/watering/>.

Nielsen, J. 2012. Alertbox: How Many Test Users in a Usability Study? 10 Sept. 2012. <http://www.useit.com/alertbox/ number-of-test-users.html>.

Nielsen, J. and R. Buidu. 2010. Usability of iPad apps and websites. 10 Sept. 2012. <http://www.nngroup.com/reports / mobile/ipad/ipad-usability_lst-edition. pdf $>$.

Roberts, K. and G. McIntosh. 2012. Use of mobile devises in extension and agricultural production-a case study. 15 July 2013. <http://www.regional.org. au/au/asa/2012/precision-agriculture/ 8224_robertsk.htm\#TopOfPage $>$. 
Southwest Plant Selector. 2012. Southwest Plant Selector (Version 1.06). 29 June 2013. <https://itunes.apple.com/ us /app / southwest-plant-selector/ id526449181 ? ls $=1 \& \mathrm{mt}=8>$.

Southwest Plant Selector. 2013. Southwest Plant Selector App for the iPhone. 28 June 2013. <http://www.xericenter. com/swplants $/>$.

SQLite. 2013. SQLite Download Page. 28 June 2013. <http://www.sqlite.org/ download.html $>$.

Survey Console. 2013. Online Surveys. 28 June 2013. <http://www.surveyconsole. com/console/home.do $>$.
Teoh, K.O. 2009. Explorations on web usability. Amer. J. Appl. Sci. 6:424-429.

TestFlight. 2013. Beta Testing on the Fly. 28 June 2013. <https://testflightapp. $\mathrm{com} />$.

U.S. Department of Agriculture. 2012. USDA Hardiness Zones Interactive Map. 12 Sept. 2012. <http://planthardiness. ars.usda.gov/PHZMWeb/\#>.

Viswanathan, P. 2012. Ways to Increase Your iPhone App Ranking in the Apple App Store. 10 Sept. 2012. <http://mobiledevices.about.com/od/ marketingapps/tp/Ways-To-Increase-
Your-Iphone-App-Ranking-In-The-AppleApp-Store.htm>.

Western Regional Climate Center. 2012. Climate of New Mexico. 10 Sept. 2012. $<$ http://www.wrcc.dri.edu/narratives/ newmexico/>

Zibreg, C. 2012. Apple shuts down Chomp website and iOS app. 28 June 2013. <http://www.idownloadblog. com $/ 2012 / 10 / 01 /$ apple-shuts-downchomp/>. 